Review

\title{
Review of Research on Digital Supply Chain Management Using Network Text Analysis
}

\author{
Jebum Pyun ${ }^{1}$ and Jin Sung Rha ${ }^{2, * \mathbb{C}}$ \\ 1 Department of Big Data and AI, Hoseo University, Asan 31499, Korea; pjb@hoseo.edu \\ 2 School of Business Administration, Dankook University, Yongin 16890, Korea \\ * Correspondence: jinsungrha@dankook.ac.kr; Tel.: +82-31-8005-3417
}

check for

updates

Citation: Pyun, J.; Rha, J.S. Review of Research on Digital Supply Chain Management Using Network Text Analysis. Sustainability 2021, 13, 9929. https://doi.org/10.3390/su13179929

Academic Editor: Nicola Saccani

Received: 12 August 2021

Accepted: 1 September 2021

Published: 3 September 2021

Publisher's Note: MDPI stays neutral with regard to jurisdictional claims in published maps and institutional affiliations.

Copyright: (C) 2021 by the authors. Licensee MDPI, Basel, Switzerland. This article is an open access article distributed under the terms and conditions of the Creative Commons Attribution (CC BY) license (https:// creativecommons.org/licenses/by/ $4.0 /)$.

\begin{abstract}
Studies that have examined the digital transformation's association with supply chains have been actively conducted for over 10 years, and studies on digital supply chain management have been increasing. However, there is a lack of consensus on the definitions of or views about the digital supply chain; thus, researchers in the academic or industrial fields propound various concepts of digital supply chains, which results in confusion during the exchange of opinions or transmission of concepts in many cases. The purpose of this study is to identify the research trends from various articles on the digital supply chain that have been published so far, summarize and analyze the theories and concepts pertaining to it, and review future topics of research. Network text analysis was conducted by extracting information from unstructured text data to identify research trends. The results of the analysis showed that many studies have examined the digital supply chain in terms of sustainable management. "Sustainability" was the most influential word in the keyword network, and the digital transformation of supply chains is essential for the sustainable viability of firms in the era of Industry 4.0 and digital transformation. Many studies have focused on technology for big data analysis and the IoT as technologies to fulfill digital supply chains and maintained that COVID-19 has increased risk factors such as global supply chain disruptions, which is why global firms must monitor the supply chain in real time by securing end-to-end visibility and making corporate-level efforts to build a digital supply chain to instantly detect and deal with related risks. The common groups of keywords were related to "supply chain integration", "resilience", "digital technologies", and "digital transformation".
\end{abstract}

Keywords: digital supply chain management; digital transformation; network text analysis; research trend; sustainable supply chain management

\section{Introduction}

The Fourth Industrial Revolution is changing not only various countries' industrial structures, but also overall business processes and models. In some ways, these changes are advanced by technological development, but they can also be regarded as the efforts made voluntarily by firms to survive and cope with rapid changes in customer demands, such as increased needs for personalized and diversified products, the diversification of purchasing methods, and the convergence of products with services. As opposed to the earlier method of producing goods based on production plans that depended on market demands, these efforts are made with the digitalization of processes through the sharing of real-time information based on digital connectivity, which we know as well as the concept of digital transformation.

Studies that have examined the digital transformation's association with supply chains have been actively conducted for over 10 years, and studies on digital supply chain management have been increasing. However, there is a lack of consensus on the definitions of or views about the digital supply chain; thus, researchers in the academic or industrial fields propound various concepts of digital supply chains, which results in confusion 
during the exchange of opinions or transmission of concepts in many cases. Scholars tend to perceive the development of digital supply chains as a concept that advocates that supply chain operations are advanced by quickly evolving technology, whereas industrial experts working in famous consulting firms focus on changes in business models in accordance with the concept of digital supply chains from the perspective of digitalization of processes. Then, most engineers in manufacturing firms think of the digital supply chain as a limited concept involving the mere application of digital technology to the operation of production facilities and equipment.

As these different groups of experts perceive the digitalization of the supply chain from their own perspectives and situations, there are occasional hindrances to smooth communication or exchange of opinions. Therefore, it is necessary to comprehensively analyze research findings of studies on the digital supply chain, organize concepts pertaining to the same, and derive consistent theories based on these concepts. Moreover, the COVID-19 pandemic has caused the destruction of economies and supply chains across the world. There has been an awareness of how the extant techniques of operation of supply chains are limited during the pandemic, and the digital supply chain, which has drawn the attention of experts, has been suggested as a solution to the problem. Therefore, it is necessary to comprehensively analyze various research findings about the digital supply chain and systematically organize the unorganized concepts because there are various definitions and discussions concerning digital supply chains.

The purpose of this study is to identify the research trends from various articles on the digital supply chain that have been published so far, summarize and analyze the theories and concepts pertaining to it, and review future topics of research. Network text analysis was conducted by extracting information from unstructured text data to identify research trends. Instead of analyzing previous studies based on the researcher's subjectivity, the research trends were objectively identified using various indicators obtained from network analysis.

Chapter 2 summarizes the concepts and applications of the digital supply chain based on previous studies. Chapter 3 describes the methods of network text analysis, and Chapter 4 provides the results of analyzing the research trends. Chapter 5 summarizes the results of the analysis and explains the implications and limitations of the study. This study used Net Miner 4.0 for network text analysis.

\section{Digital Supply Chain}

\subsection{Definition of a Digital Supply Chain}

The definitions and concepts pertaining to a digital supply chain explained in various studies share the common factor that it is an "advancement in supply chain operations using advanced digital technology." However, the definitions vary slightly in terms of its use. This can be examined from the following three perspectives.

The first definition emphasizes the transformation of business processes using digital technology. Studies mentioning this concept emphasize the fact that new values must be created by transforming paper-based business processes into smart business processes while also emphasizing the need to carry out corresponding organizational transformations. Garay-Rondero et al. [1] defined a digital supply chain as a proactively executable platform (or a supply chain focused on the ecosystem) on which all firms in the supply chain can collect and analyze real-time data inside and outside the supply chain by using Information and Communications Technology (ICT) and new analytical techniques. Daniel [2] defined it as a web-based supply chain that breaks away from the conventional method of mixing paperwork-based and IT-based processes, emphasizing that features such as connection, system integration, and data generation from smart components must be completely usable. Kinnet [3] defined a digital supply chain as a value-oriented intelligent network that embraces analysis and technology using new approaches to generate fresh profits and business value. Wu et al. [4] defined it as a new concept of interconnected business systems expanding from isolated and local single-firm applications to a supply chain where 
extensive and systematic smart technologies are implemented. They emphasize the fact that all stages of a supply chain are connected, which enables robust data collection as well as intelligent decision making based on real-time communication; it also requires an efficient system based on immediate responses to provide better customer services. The multinational firm PricewaterhouseCoopers $(\mathrm{PwC})$ defines a digital supply chain as a system that focuses on the digital connection of all physical assets beyond the automation of each machine and process, as well as integration into digital ecosystems with value chain partners [5]. Agile Elephant [6] defines the digital supply chain as the concept of digital transformation that is the process of transforming the traditional approach to working and thinking into a new method using digital media, social networks, mobile channels, and newly emerging technologies.

The second definition focuses on collaboration using digital technology. Studies mention that this concept emphasizes the operation of digital platforms (or digital networks) through collaboration to collect and share extensive information and create new supply chain opportunities using digital technologies among the entities in the supply chain (or among supply chains themselves). Büyüközkan and Göçer [7] defined digital supply chains as intelligent optimized-technology systems that perform functions such as massive data processing and excellent collaboration and communication using digital hardware and software that synchronize and support interactions among organizations. They mention that services can be more valuable, accessible, and reasonably priced while also performing with consistency, agility, and efficacy. Bhargava et al. [8] defined a digital supply chain as the system that mediates partner activities in the supply chain through software, hardware, and a communication network to support interactions in the processes such as purchase, production, storage, transport, and sale of goods among organizations across the world. Raab and Griffin-Cryan [9] pointed out issues such as the amalgamation of both electronic and paper-based processes and the functional and geographical silo effect. They defined a digital supply chain as a system designed to improve the stability, agility, and efficiency of supply chains by enabling the use of extensive information and excellent collaboration and communication throughout the digital platform. A few institutes studying supply chains defined a digital supply chain as a customer-centered platform that captures real-time information from various sources and maximizes its use [10]. It can optimize performance and minimize risks through demand stimulation, matching, detection, and management [11,12]. Furthermore, digitalization of the supply chain has the potential to make services more valuable, accessible, and reasonably priced. Thus, organizations must reconstruct and implement current tasks in a digital supply network and cloud environment that integrates human resources and information in addition to the physical flow of goods and services in the supply chain to create new supply chain opportunities $[13,14]$. To focus more on creating additional customer values than on the visibility and transparency of knowledge obtained from big data and vast information systems, managers need to recommend that analysts must be drawn to find hidden meanings from them and perfectly understand these development procedures to arrive at the right conclusions, thereby leading to the growth of a data-based firm that can generate the necessary performance measures that will positively impact business results [15].

The third definition focuses on advancements in operations management using digital technology, and studies mentioning this concept emphasize the agile adjustment of processes by achieving a two-way process of detecting and responding to market changes based on real-time information using digital technology while also stressing the importance of minimizing waste and risks in the supply chain by maximizing the use of digital technology. In other words, it is the process of changing and reacting according to the market condition by means of two-way detection, response, and adjustment due to emerging technologies [16-18]. To this end, it is necessary to construct value chains connected to a single ecosystem using advanced digital technologies such as big data analysis, Internet of Things (IoT), cloud computing, sensor networks, 3D printing Virtual Reality (VR)/ Augmented Reality (AR), and blockchain [19]. As a result, products or services that use smart sen- 
sors or network features must be provided to build digitalized business models based on integrated vertical and horizontal value chains (e.g., data-based services and integrated platform solutions) [5]. Ivanov et al. [20] defined a digital supply chain as a system that performs functions such as plan, source, make, and deliver, as presented by the SCOR model with big data analytics, CPS-based networks, additive manufacturing, and advanced tracking and tracing systems, and they mentioned that IoT, blockchain, cloud technology, robots, and sensor technology can promote technical performance. Calatayud et al. [21] defined a digital supply chain as a self-thinking supply chain that constantly monitors performance by both predicting and detecting risks by analyzing massive data collected from various sources and actively taking preventive actions before the occurrence of risks, claiming that it tends to learn from these activities and use the knowledge in future decision making. In a report written with WHU-Otto Beisheim School of Management, A.T. Kearney [22] introduced a digital supply chain as the optimal technology that supports and synchronizes supply chain processes to minimize waste occurring in the environment as a result of high-demand fluctuations and risks, mentioning that this technology includes warehouse and transport management systems, radio frequency identification (RFID), advanced picking technology, and innovative scheduling systems.

\subsection{Development Trends and Application of Digital Supply Chains}

The most recent economic problem to have arisen is the limitation of various economic activities due to COVID-19. As COVID-19 became a new risk factor that could disrupt the supply chain in the process of supplying raw materials and components or distributing and delivering finished goods, many countries and firms suffered great losses. In fact, the slowdown of economic activities shrunk the GDP by $4.2 \%$ on average worldwide, $3.8 \%$ in the US, and 7.5\% in Europe [23]. Simchi-Levi and Simchi-Levi [24] pointed out that the traditional supply chain management technique that pursues efficient mass production based on demand forecasting to reduce inventories and costs is not enough to deal with this disruption in supply chains. In particular, current supply chains need to be redesigned to quickly overcome this disruption and recover original functions [25]. Moreover, the strong infectivity and frequently surfacing variants of the coronavirus will accelerate the trend of customer demands being met via contactless channels, which will bring inevitable changes to business operations and national economic activities.

To overcome these problems, multinational companies such as Amazon, BMW, Alibaba, and Lufthansa are striving to make large investments and develop technologies for the digitalization of supply chains [26]. Amazon has been most actively making investments in hardware and software for the digitalization of supply chains. Starting with the acquisition of Kiva Systems in 2012, Amazon established the foundation for automatic logistics systems by introducing over 20,000 robots in 175 fulfillment centers throughout the US in 2020 [27] and actualizing the automation of delivery by releasing the delivery robot Scout in Seattle in January 2019 [28]. Amazon is also operating a browser-based cloud service using 3D and VR/AR technology called Amazon Sumerian to overcome the "limitations of experience," which is a limitation of e-commerce, with a business model that can lead customers to actual purchase by giving them a virtual experience beforehand [29]. The manufacturer BMW implements a cloud-based supply chain that allows the receipt of production schedules from suppliers and updates arrival data from forwarders every 15 min, thereby recording the supply and delivery status in real time [30]. If there is a serious delay due to an accident anywhere in the supply chain, it secures the visibility of the supply chain by simultaneously identifying the location of the site of accident using the global positioning system (GPS) data, recalculating the delivery time, determining the potentially insufficient number of products in the warehouses, and reshuffling alternative modes of transportation [22]. Samsung SDS, an ICT and system integration (SI) company in Korea, established an artificial intelligence (AI)/machine learning (ML)-based demand forecasting automation system, in-memory scenario planning, and a data analysis system through a mobile interface and platforms to share information with the various entities 
in the supply chain, thereby developing and providing solutions to cope quickly and efficiently with major events that occur in the entire process of the supply chain and build an operating system that helps promote quick decision making and collaboration among departments [31]. As such, the operative solution for supply chain management is developing through vertical/horizontal integration so that the chain has the general analytical skills and functions to manage flexible and resilient supply chains that can respond to rapidly changing market situations and analyze and cope with their effects in real time [32].

For drastic change and innovation in digital supply chains, efforts are being made for preparations not just at the corporate level but also at the national level. The UK government is pushing forward a research project on smart production-driven digital supply chains to increase the productivity of supply chains for manufacturing in the UK by the United Kingdom Research and Innovation (UKRI) under the Department for Business, Energy, and Industrial Strategy (BEIS) to overcome the vulnerability of supply chains exposed due to COVID-19 [33]. This project emphasizes the need to improve and redesign supply chains by building digital supply chains and an efficient supply chain system to enhance forecasting information related to the supply and demand of products by applying the latest technologies such as IoT, cloud computing, AI, 3D printing, and robotics to extant supply chains. In addition, the goal of the project is to create a system that can track products in real time in the supply chain using digital technologies such as cost-effective sensors, near field communication (NFC), and real-time data collection and analysis [28]. Through innovations in functions in a supply chain, such as data analysis, modeling, and connectivity, the UK is expected to significantly improve its capability to manage supply chains and improve corporate technologies to manage the global supply chain. This government's task is supported by its Industrial Strategy Challenge Fund, and it provides small and medium-sized enterprises (SMEs) with grants ranging between 250,000 and 3 million pounds for technology development and manufacturing [33].

Meanwhile, Japan has carried forward the Smart Supply Chain (Manufacturing) strategy as part of "Society 5.0" in order to create innovative products and services suitable for demand from the individual consumer by constructing a 'Real Data Platform' that can collect and use real-time data in all stages of product development, manufacturing, sales, and consumption, and realize the highly safe and productive manufacturing processes by operating smart factories based on data connection [34]. For this, Japan has established the Digital Agency in 2021 and has been reforming its systems so that firms can use data in a fair and liberal environment by actively supporting the implementation of IoT in SMEs [34]. In particular, the Japanese government is implementing a curriculum to support human resources in the manufacturing business for them to acquire digital skills in collaboration with Germany.

In the US, President Joe Biden ordered the inspection of supply chain risks to prepare for supply interruption due to auto-semiconductor shortages while also giving special instructions to determine American companies' dependency on China for overseas suppliers. He particularly asked to identify global production and logistics networks by completing inspections within 100 days for semiconductor chips for consumer goods, electric vehicle batteries, and rare materials for electronics. Moreover, by meeting the CEOs of semiconductor manufacturers, automakers, and other companies using semiconductors in the US that are affected by semiconductor shortages, he listened to the voices of the industry that advocated that the government must invest in and establish future infrastructure to promote supply chain resilience, thereby seeking support for supply chain management at the administrative level [35]. 


\section{Methods}

\subsection{Network Text Analysis}

This study conducted a network text analysis to identify research trends in studies on digital supply chain management. Network text analysis is a methodology that combines text mining and network analysis, deconstructs texts by elements such as keywords, authors, and articles, and uses them as nodes to establish and analyze various networks. Most conventional research trend analyses classify research articles based on theories, methodologies, or even the researcher's subjectivity. Therefore, the results of the analyses may vary depending on the criteria initially set by the researcher. On the other hand, key elements of research articles comprising unstructured text data can be quantified using network text analysis in the analysis of research trends, which enables objective analysis.

Many studies have recently analyzed research trends in subtopics pertaining to supply chain management using network analysis. Fahimnia et al. [36] searched research articles on Scopus, an academic database, formed citation and co-citation networks using the articles as nodes, and conducted PageRank and cluster analysis to identify major research groups and influential articles in green supply chain management. Fahimnia et al. [37] analyzed major research articles and topic clusters in studies on supply chain risk management. Feng et al. [38] extracted 4915 main keywords from articles studying corporate social responsibility in the supply chain to build a keyword network and identified five major topic clusters using the Force Atlas algorithm. Rha [39] searched 808 articles on Scopus to identify the research trends in supply chain resilience, determined the major groups of authors by analyzing co-authorship networks with authors as nodes, and classified the articles by the dates they were published on and analyzed the keyword network to examine the changes in major research topics.

\subsection{Procedures of Network Text Analysis}

This study conducted a network text analysis using the following procedures based on previous studies. First, an academic database was selected, and articles for analysis were searched on that database. Many analyses of research trends used databases such as Google Scholar, Scopus, and Web of Science. This study searched for articles on digital supply chains on Scopus. Scopus is a database that includes the largest number of journals in social science, providing bibliometric data of articles in a way that can be easily identified by researchers. Second, keywords and author data were extracted from the searched articles. Scopus provides both keywords presented by researchers as well as indexed keywords standardized by Scopus. This study used the former, which required keyword cleansing. For example, researchers used different terms that have the same meaning, such as "supply chain resilience", "resilient supply chain", and "supply chain resiliency". In this case, the terms were unified as one. Compounds such as "Supply Chain Innovation" and "Innovative Supply Chain Management" must also be unified into words such as "Innovation", depending on the meaning, to increase the accuracy of text analysis. Two experts on digital supply chain management advised on the consistency and cleansing of terms. Third, networks were built using keyword data. The network that could be built first was a two-mode network comprising articles and keywords. A two-mode network is represented by two dimensions of nodes. For example, in the case of a network comprising article nodes and keyword nodes, when article A presents keywords a and $b$, article node $\mathrm{A}$ and keyword nodes $\mathrm{a}$ and $\mathrm{b}$ are linked. In a two-mode network, article nodes and keyword nodes can be linked together, but not one article to another, or one keyword to another. Therefore, to systematically analyze keywords by building a keyword network, it is necessary to build a one-mode network in which keyword nodes can be linked to one another. The algorithm to transform the two-mode network was comprised of article and keyword nodes that changed into a one-mode network comprising only keyword nodes based on the co-occurrence of keywords. For example, if articles A, B, and C all presented keywords $a$ and $b$, these keywords were in co-occurrence and, thus, they were highly correlated. In this case, the keyword nodes $\mathrm{a}$ and $\mathrm{b}$ are linked in the keyword network. In 
this study, cosine similarity was used to measure the intensity of co-occurrence. For the authorship network, the two-mode network of articles and authors was transformed into a one-mode network comprising only the authors. Fourth, social network analysis was conducted using the keyword and authorship networks. This study calculated the degree centrality and betweenness centrality to identify the impact of nodes in the network. Degree centrality shows how different nodes may be linked to a specific node, and betweenness centrality shows how a specific node mediates other nodes. The formula for each centrality and the meaning of centrality in the analysis of research trends are explained in Section 3. Cluster analysis was conducted after analyzing centrality. Cluster analysis examined whether nodes in a network could be divided into groups. Node sets were found by classifying them such that there were more links within node groups than between groups. The group of research topics can be inferred from the group of keyword nodes through cluster analysis. This study conducted a cluster analysis based on the method presented by Blondel et al. [40]. Table 1 summarizes the procedures of network text analysis.

Table 1. Procedures of network text analysis.

\begin{tabular}{cc}
\hline Procedures & Descriptions \\
\hline $\begin{array}{c}\text { Selecting the academic database } \\
\text { and searching articles }\end{array}$ & $\begin{array}{c}\text { Using the world-renowned academic database Scopus } \\
\text { Searching articles using search words related to "digital } \\
\text { supply chain" }\end{array}$ \\
\hline Extracting keyword & $\begin{array}{c}\text { Using keywords presented by the author } \\
\text { Cleansing keywords to increase accuracy of analysis }\end{array}$ \\
\hline Conducting network analysis keyword network & $\begin{array}{c}\text { Building a two-mode network of article-keyword } \\
\text { Building a one-mode network based on co-occurrence } \\
\text { Using cosine similarity as an algorithm for transformation }\end{array}$ \\
\hline & $\begin{array}{c}\text { Analyzing keyword one-mode network } \\
\text { Calculating degree centrality and betweenness centrality } \\
\text { Identifying network clusters through community analysis } \\
\text { Identifying research trends by analyzing the keyword group }\end{array}$ \\
\hline
\end{tabular}

\section{Results}

\subsection{Subject Analysis}

This study used the world-renowned academic database Scopus to search for articles on digital supply chain management. Articles were searched using "digital supply chain", "supply chain digitalization", "supply chain digitalisation", and "supply chain digitization" as search words from journals including "Business, Management, and Accounting", "Decision Sciences", and "Social Sciences" on Scopus. Since the purpose of this study was to identify the research trends, only articles published in journals and those written in English were analyzed for convenience in analysis. Ultimately, 815 articles were included in the analysis. Figure 1 shows 815 articles by year of publication. Since 2010, studies on digital supply chain management have been increasingly published, and numbers have rapidly risen since 2015, when digital transformation began to be discussed in earnest. Since this study searched for articles published until May 2021, the number of articles on digital supply chains ultimately published in 2021 will be much higher than the numbers quoted in Figure 1. Table 2 shows the major journals that published the articles, and Table 3 lists the major authors.

\subsection{Network Text Analysis on Articles Published until 2019}

\subsubsection{Building the Keyword Network}

This study identified the research trends by dividing the subjects into two groups: articles published until 2019 and articles published since 2020. The time period is divided as such because COVID-19 may have had a considerable impact on studies on digital supply chain management. COVID-19 broke out in November 2019 and has brought changes to the living environment of the entire world and directly hit the global economy since 
the second quarter of 2020. Therefore, this study assumed that COVID-19 has brought considerable changes to global supply chains and, thus, researchers might have conducted research on the topic from new perspectives.

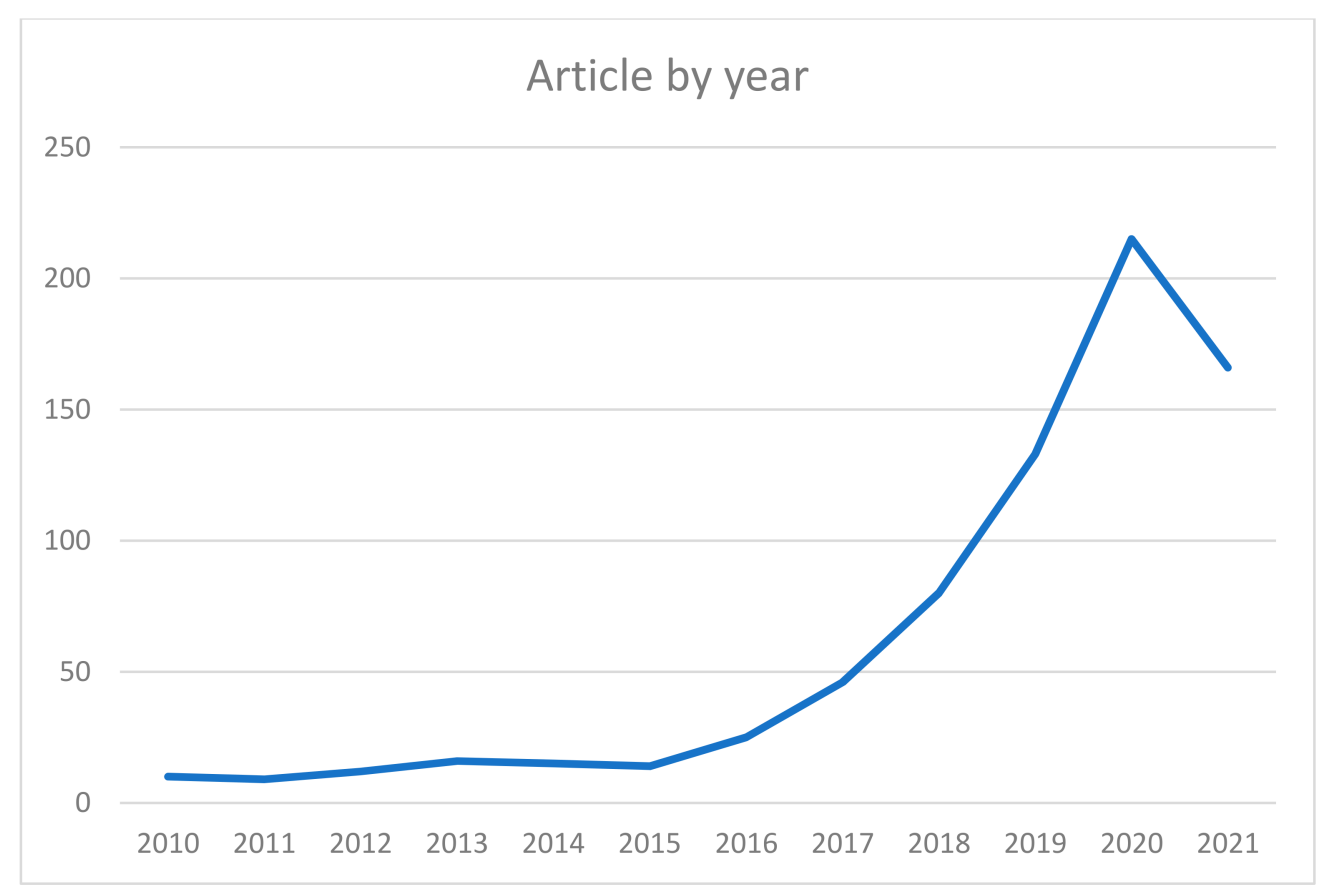

Figure 1. Articles by year.

Table 2. Major journals publishing digital supply chain articles.

\begin{tabular}{|c|c|}
\hline Source Title & Number of Articles \\
\hline International Journal of Supply Chain Management & 60 \\
\hline Sustainability & 40 \\
\hline International Journal of Production Economics & 31 \\
\hline Journal of Cleaner Production & 30 \\
\hline International Journal of Production Research & 29 \\
\hline Production Planning and Control & 26 \\
\hline Supply Chain Management & 17 \\
\hline International Journal of Logistics Management & 11 \\
\hline Supply Chain Forum & 11 \\
\hline Technological Forecasting and Social Change & 11 \\
\hline IEEE Transactions on Engineering Management & 10 \\
\hline Industrial Management and Data Systems & 10 \\
\hline Benchmarking & 9 \\
\hline International Journal of Information Management & 9 \\
\hline Journal of Manufacturing Technology Management & 9 \\
\hline Annals of Operations Research & 8 \\
\hline European Journal of Operational Research & 8 \\
\hline International Journal of Physical Distribution and Logistics Management & 8 \\
\hline
\end{tabular}


Table 3. Major authors publishing digital supply chain management articles.

\begin{tabular}{cc}
\hline Author & Number of Articles \\
\hline Ivanov, D. & 10 \\
\hline Kumar, S. & 7 \\
\hline Gunasekaran, A. & 6 \\
\hline Dolgui, A. & 6 \\
\hline Sarkis, J. & 6 \\
\hline Graham, G. & 5 \\
\hline Tsolakis, N. & 5 \\
\hline Queiroz, M.M. & 4 \\
\hline Kolesnikov, A.V. & 4 \\
\hline Ukolov, V.F. & 4 \\
\hline Barykin, S.Y. & 4 \\
\hline Luthra, S. & 4 \\
\hline Srai, J.S. & 4 \\
\hline Holmström, J. & 4 \\
\hline Rai, A. &
\end{tabular}

A total of 434 of 815 articles were published up to and including 2019. These articles presented a total of 1625 keywords. Figure 2 shows the word cloud based on the frequency of the keywords. Larger keywords indicate a higher frequency. The keywords with high frequency included "sustainability", "blockchain", "Industry 4.0", "supply chain integration", "big data", and "Internet of Things.

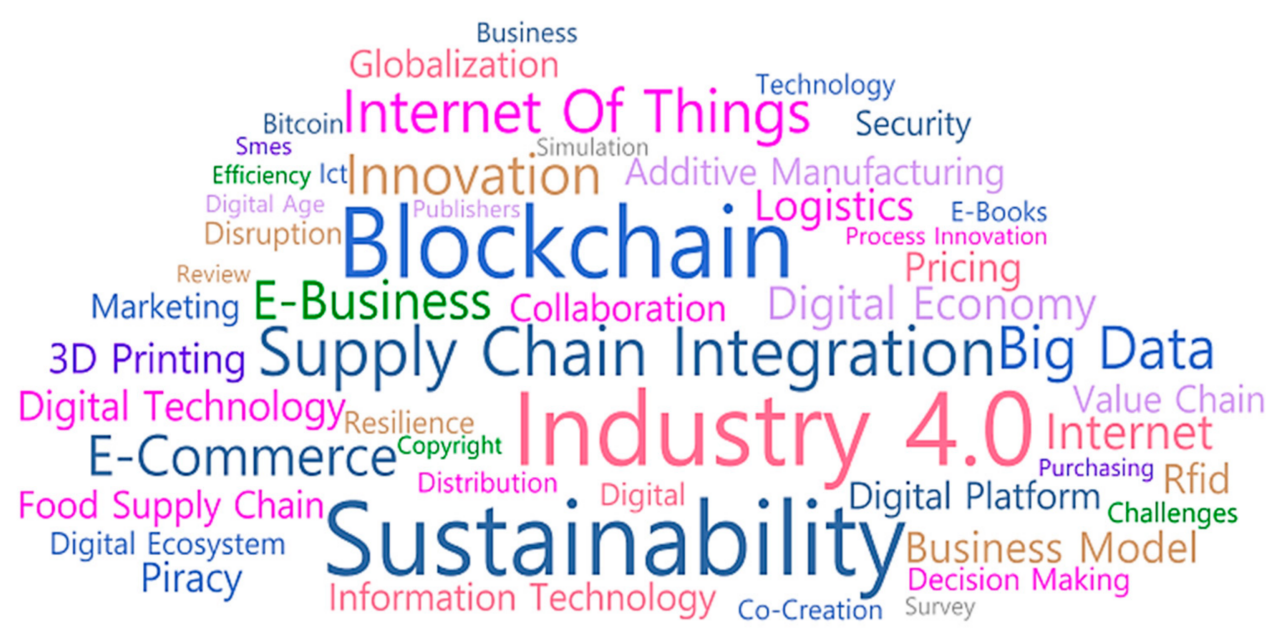

Figure 2. Word cloud (until 2019).

For significant analysis, this study built a two-mode network comprising article and keyword nodes with keywords that appeared at least three times in 434 articles. As a result, most articles shared keywords, and a few articles, not sharing keywords with the other articles, were separated from the two-mode network. This shows that articles on digital supply chains form a giant community.

Cosine similarity was calculated to transform the two-mode network comprising articles and keywords into a one-mode network comprising only keywords. The formula for cosine similarity is as shown in Equation (1), and the cut-off value of cosine similarity was set as 0.2 to link the co-occurring keywords. Figure 3 shows a one-mode network comprising only keyword nodes. 


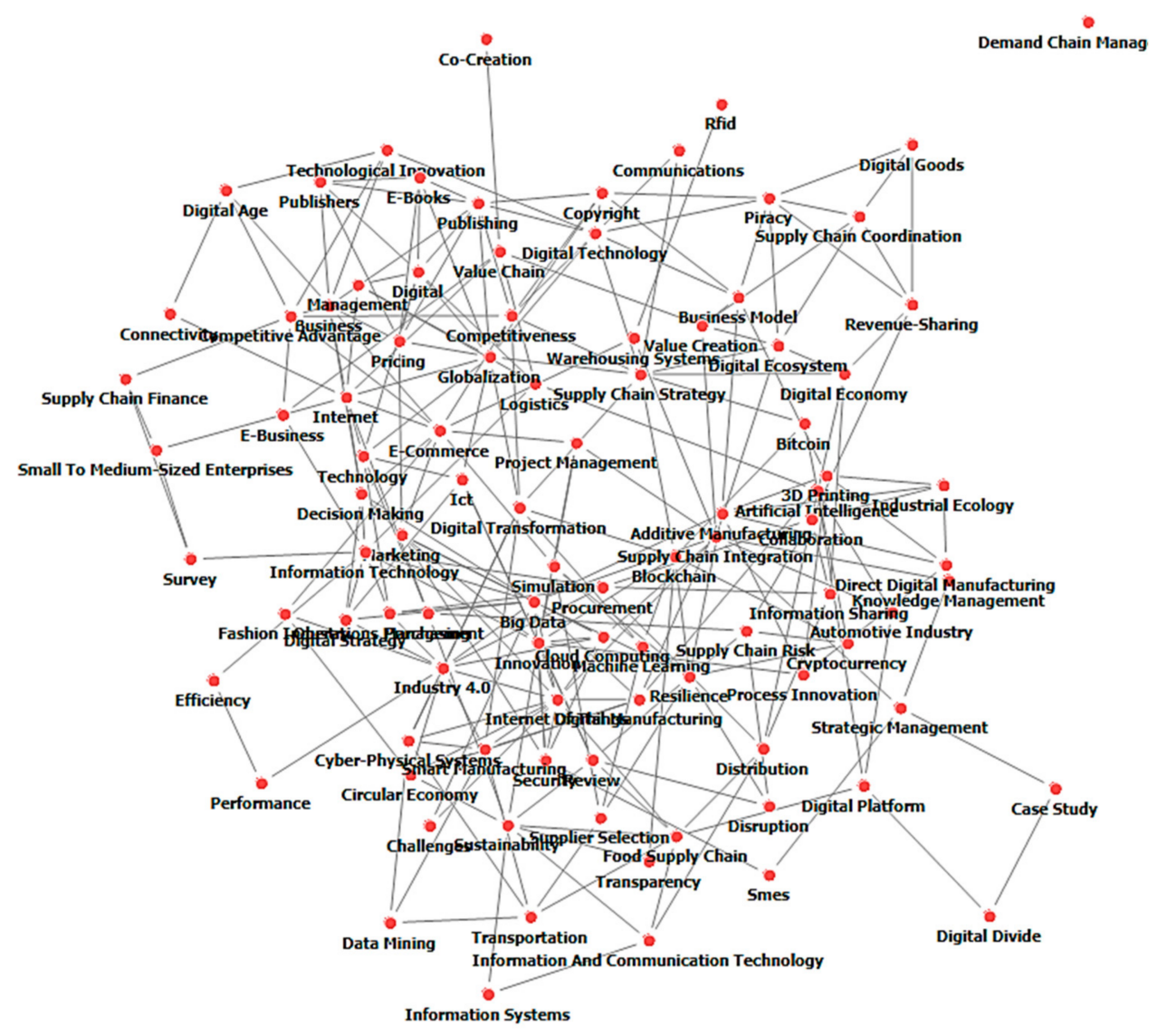

Figure 3. Keyword network (until 2019).

Equation (1) Cosine Similarity

$$
\text { Cosine Similarity }=\frac{\sum_{k=1}^{n} C_{i k} C_{j k}}{\sqrt{\sum_{k=1}^{n} C_{i k}^{2}} \sqrt{\sum_{k=1}^{n} C_{j k}^{2}}}
$$

$\left(C_{i k}=\right.$ number of occurrences of keyword $i, C_{j k}=$ number of occurrences of keyword $\left.j\right)$.

\subsubsection{Centrality Analysis}

Centrality analysis was conducted to identify the effects of each keyword node in the keyword network. Degree centrality and betweenness centrality were calculated among various centrality indices. Their formulas are shown as Equations (2) and (3). Keyword nodes with a high degree of centrality in the keyword network were highly correlated with subtopics that are most frequently covered in studies on digital supply chains. Keyword nodes with high betweenness centrality are highly correlated with topics that mediate subtopics or have high expandability.

Equation (2) Degree Centrality

$$
\text { Degree Centrality }=\frac{\sum \text { Weight of Incident Links }}{\text { Number of Nodes }-1}
$$

Equation (3) Betweenness Centrality

$$
\text { Betweenness Centrality }=\frac{\sum_{j<k} g_{j k}\left(n_{i}\right) / g_{j k}}{\left[\frac{(g-1)(g-2)}{2}\right]}
$$


( $g_{j k}=$ the number of shortest paths that connect nodes $j$ and $k, g_{j k}\left(n_{i}\right)=$ the number of paths that pass through node $i$ among the shortest paths that connect nodes $j$ and $k$, $[(g-1)(g-2) / 2]=$ the number of all node pairs not including $\left.n_{i}\right)$.

The results of the degree centrality analysis are presented in Table 4. Keywords with high degree centrality included "big data", "Internet of Things", "globalization", "Industry 4.0", and "innovation". This suggests that many studies have focused on technology for big data analysis and the IoT as technologies to fulfill digital supply chains, and that studies on digital supply chain management have been conducted in terms of innovation due to the influence of Industry 4.0 as a mega trend as well as the globalization of supply chains. The results of the betweenness centrality analysis are presented in Table 5 . The results were mostly similar to those of the degree centrality analysis, with "supply chain integration" mediating the largest number of keywords. This implies that many studies on digital supply chains consider digitalization as a means and strategy to optimize supply chain integration and maximize its performance.

Table 4. Degree centrality analysis (until 2019).

\begin{tabular}{|c|c|}
\hline Keywords & Degree Centrality \\
\hline Big Data & 0.145833 \\
\hline Internet of Things & 0.135417 \\
\hline Globalization & 0.135417 \\
\hline Industry 4.0 & 0.125 \\
\hline Innovation & 0.125 \\
\hline Resilience & 0.104167 \\
\hline E-Commerce & 0.104167 \\
\hline Supply Chain Integration & 0.104167 \\
\hline Information Technology & 0.104167 \\
\hline Internet & 0.104167 \\
\hline Digital Technology & 0.09375 \\
\hline Supply Chain Strategy & 0.09375 \\
\hline Business & 0.09375 \\
\hline Publishing & 0.09375 \\
\hline Blockchain & 0.083333 \\
\hline Digital & 0.083333 \\
\hline Digital Transformation & 0.083333 \\
\hline Sustainability & 0.083333 \\
\hline Additive Manufacturing & 0.083333 \\
\hline Marketing & 0.083333 \\
\hline Smart Manufacturing & 0.083333 \\
\hline Competitiveness & 0.083333 \\
\hline
\end{tabular}

\subsubsection{Cluster Analysis}

Cluster analysis was conducted to determine how structurally the keyword nodes formed groups based on the keyword network. It was conducted using the algorithm formulated by Blondel et al. [40] and provided by NetMiner4, and clusters with less than five keywords were excluded from the analysis. Figure 4 shows six clusters of keyword nodes formed in the network, and Table 6 summarizes the main keywords by cluster. 
Table 5. Betweenness centrality analysis (until 2019).

\begin{tabular}{cc}
\hline Keywords & Node Betweenness Centrality \\
\hline Supply Chain Integration & 0.130157 \\
\hline Big Data & 0.106023 \\
\hline Information Technology & 0.089664 \\
\hline Innovation & 0.080355 \\
\hline Internet & 0.078466 \\
\hline Globalization & 0.076832 \\
\hline Internet of Things & 0.067257 \\
\hline E-Commerce & 0.067026 \\
\hline Supply Chain Strategy & 0.062592 \\
\hline Industry 4.0 & 0.053164 \\
\hline Resilience & 0.052187 \\
\hline Digital Transformation & 0.052162 \\
\hline Food Supply Chain & 0.050802 \\
\hline Sustainability & 0.048462 \\
\hline Additive Manufacturing & 0.043211 \\
\hline Digital Ecosystem & 0.038675 \\
\hline Blockchain & 0.037176 \\
\hline Collaboration & 0.037022 \\
\hline Digital Technology & 0.035983 \\
\hline Value Chain & 0.035457 \\
\hline Logistics & 0.033814 \\
\hline Marketing & 0.033204 \\
\hline
\end{tabular}

The first cluster includes keywords related to resilience enhancement due to increased supply chain disruptions and the need for digital supply chains from the perspective of sustainability. The major articles are as follows: Hosseini et al. [41] argued that various digital technologies are used in terms of supply chain risk management, which can reduce the frequency of supply chain disruptions and promote supply chain resilience, and according to Saberi et al. [42], the digitalization of supply chains using blockchain can help effectively manage various problems related to supply chains and secure environmental and economic sustainability.

The second cluster comprised keywords with mega trends of industrial circles, such as Industry 4.0, digital transformation, and the correlation of supply chain digitalization. Ranganathan et al. [43] propounded, as a result of empirical analysis, that digital competency is an essential element for a firm to promote competitiveness, and the increased digital transformation of supply chain management leads to more positive effects on the firm's business performance. Bienhaus and Haddud [44] associated all existing procedures, processes, capacities, and capabilities of supply chains with the emergence of the era of Industry 4.0. Thus, it is necessary to reconsider traditional theories such as value chains and consider supply chain digitalization taking into account various obstacles.

The third cluster included keywords on globalization and strategies of implementing a supply chain. Foster et al. [45] demonstrated, through interviews, that East African firms face difficulties due to a lack of digital competencies in terms of global value chain integration in three sectors (tea, tourism, and outsourcing of business processes). They also argued that there must be better accessibility to digital technology and platforms to strengthen the competitiveness of global supply chains. 


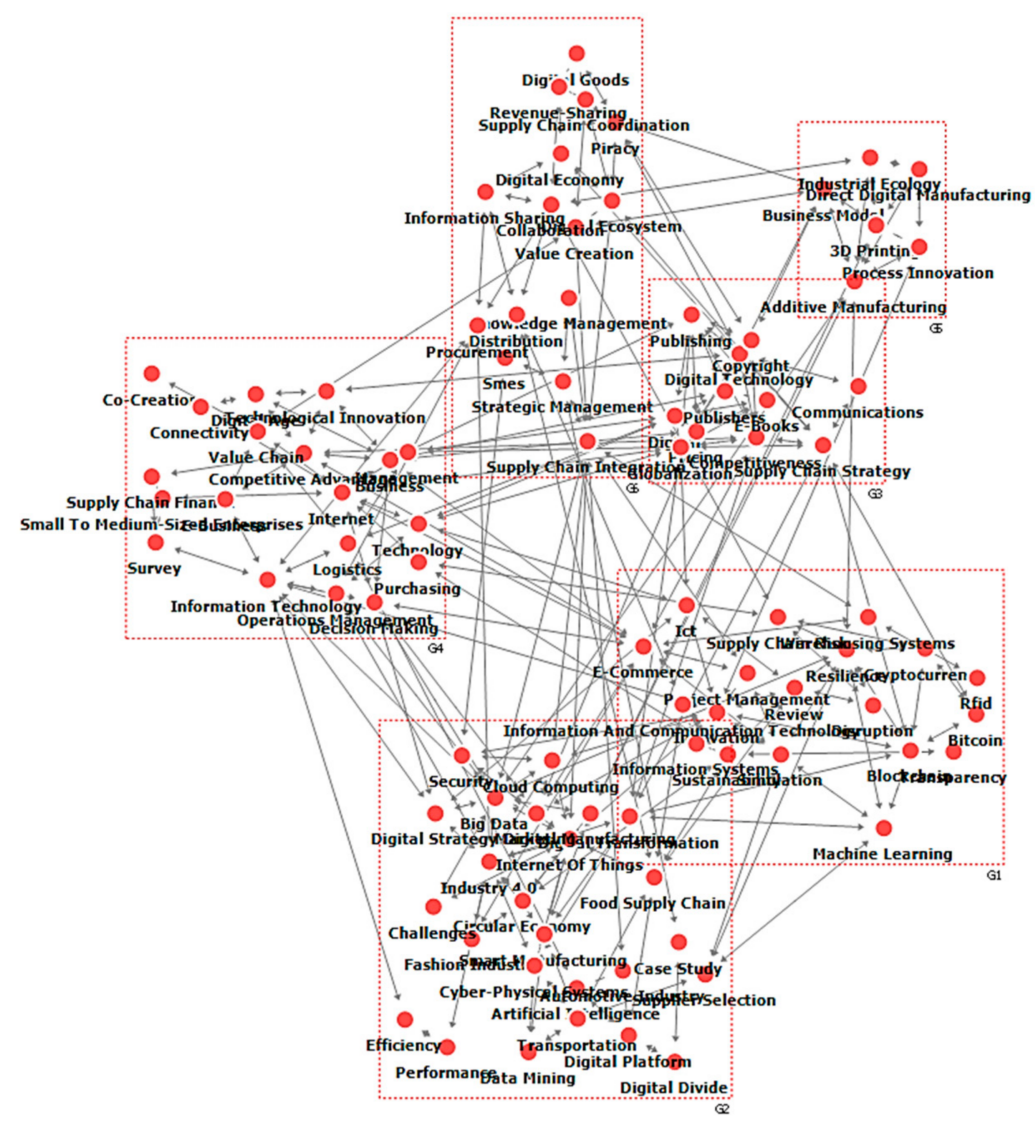

Figure 4. Cluster analysis (until 2019).

Table 6. Main keywords by cluster (until 2019).

\begin{tabular}{|c|c|c|}
\hline Cluster & Main Keywords & Related Topics \\
\hline 1 & $\begin{array}{l}\text { Blockchain, Sustainability, Innovation, } \\
\text { Disruption Resilience, Transparency }\end{array}$ & $\begin{array}{l}\text { Studies on the need to build a digital } \\
\text { supply chain to promote resilience due } \\
\text { to increased supply chain disruption } \\
\text { Studies to build a sustainable supply } \\
\text { chain by applying blockchain } \\
\text { technology with high security }\end{array}$ \\
\hline 2 & $\begin{array}{l}\text { Industry 4.0, Digital Transformation, } \\
\text { Circular Economy, Artificial Intelligence, } \\
\text { Internet of Things }\end{array}$ & $\begin{array}{l}\text { Studies on the background and triggers } \\
\text { of supply chain digitalization such as } \\
\text { Industry } 4.0 \text { and digital transformation }\end{array}$ \\
\hline 3 & $\begin{array}{l}\text { Globalization, Communication, } \\
\text { Competitiveness, Supply Chain Strategy }\end{array}$ & $\begin{array}{c}\text { Studies on communication among } \\
\text { firms based on digital technology to } \\
\text { enhance supply chain competitiveness } \\
\text { due to globalization }\end{array}$ \\
\hline 4 & $\begin{array}{l}\text { Supply Chain Integration, Supply } \\
\text { Coordination, Collaboration }\end{array}$ & $\begin{array}{l}\text { Studies on promoting collaboration by } \\
\text { building a digital supply chain for } \\
\text { supply chain integration }\end{array}$ \\
\hline 5 & $\begin{array}{l}\text { Value Chain, Competitive Advantage, } \\
\text { Supply Chain Performance }\end{array}$ & $\begin{array}{l}\text { Studies on the performances of digital } \\
\text { supply chains }\end{array}$ \\
\hline 6 & $\begin{array}{l}\text { Business Model, Additive Manufacturing, } \\
\text { 3D Printing, Process Innovation }\end{array}$ & $\begin{array}{c}\text { Studies on new business models and } \\
\text { process innovations through digital } \\
\text { manufacturing }\end{array}$ \\
\hline
\end{tabular}


The fourth cluster is mostly related to keywords related to supply chain integration and collaboration enhancement. Rai et al. [46] conducted a survey of 432 firms that showed that the intensity of supply chain process integration increased along with digitalization of the firm's infrastructure. Hsu and Wallace [47] mentioned that supply chain digitalization integrates information in the industrial network, improves the general performance in terms of operations, and helps upgrade logistics routes and supply chain scheduling.

The fifth cluster comprised keywords related to the performance of a digital supply chain. Many previous studies proved that supply chain digitalization could improve the performance of supply chains and bring about all types of innovation [43,48-50].

The final cluster included keywords on new business models and process innovations through digital manufacturing. According to Bogers et al. [51], additive manufacturing accelerates the consumer-centric business model, which decentralizes and "glocalizes" the supply chain. Holmström et al. [52] claimed that 3D printing is the core technology for digital supply chain management and enables the custom-made production of multiple items and value co-creation with other firms by strengthening the agility and responsiveness of the supply chain and process innovations.

\subsection{Network Text Analysis on Articles Published from 2020}

\subsubsection{Building the Keyword Network}

There were 381 articles on the digital supply chain published from 2020 to May 2021, which presented a total of 1250 keywords. Figure 5 shows the word cloud based on frequency. Keywords with high frequency were generally similar to the results of the analysis of articles published until 2019, but keywords such as "COVID-19", "Resilience", "Supply Chain Risk Management", and "Digital Twin" showed relatively higher frequency from 2020 onwards when compared with articles published until 2019. Thus, it can be assumed that global supply chain disruptions have increased due to lockdown and plant shutdowns in some regions due to the COVID-19 pandemic, and many studies have been conducted on supply chain digitalization to promote supply chain risk management and resilience.

A two-mode network comprising articles and keywords was built with keywords that appeared more than three times, and the results showed that most articles shared keywords and formed a giant community. Cosine similarity was used to transform the network into a one-mode network comprising only keywords, as shown in Figure 6.

\subsubsection{Centrality Analysis}

Degree centrality was analyzed based on the keyword network of articles published since 2020 on the digital supply chain. The results are presented in Table 7 . The results were generally similar to those of the articles published until 2019, but there was a relatively higher degree centrality of keywords such as "resilience", "COVID-19", "digital twin", and "risk management". This implies that COVID-19 has increased risks in supply chain management, and studies on digital supply chains are increasing as a strategy to promote supply chain resilience. Table 8 shows the results of the betweenness centrality analysis. Studies on supply chain management have grown in numbers with digital technology as a mediator.

\subsubsection{Cluster Analysis}

A cluster analysis was conducted to determine the groups of research topics. As shown in Figure 7, five clusters were formed, and the main keywords included in the clusters are as shown in Table 9. 


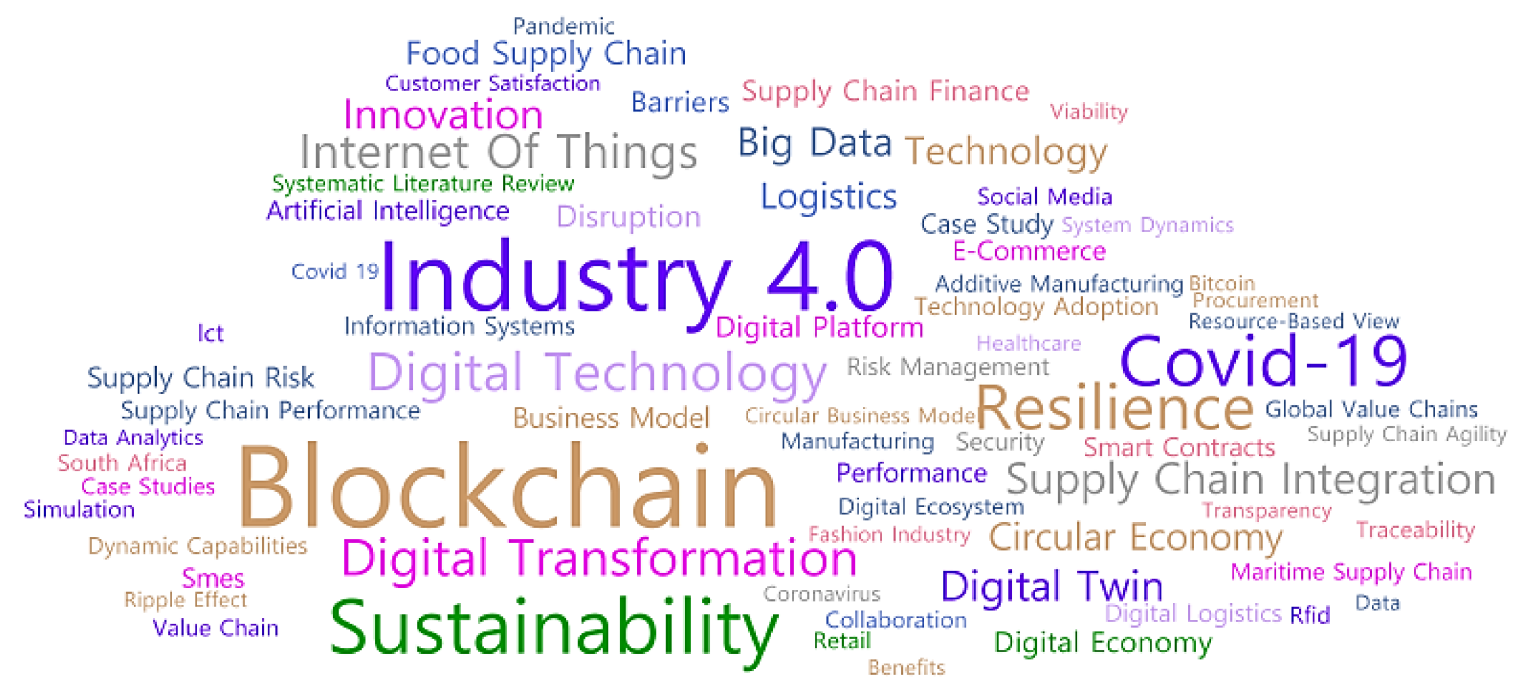

Figure 5. Word cloud.

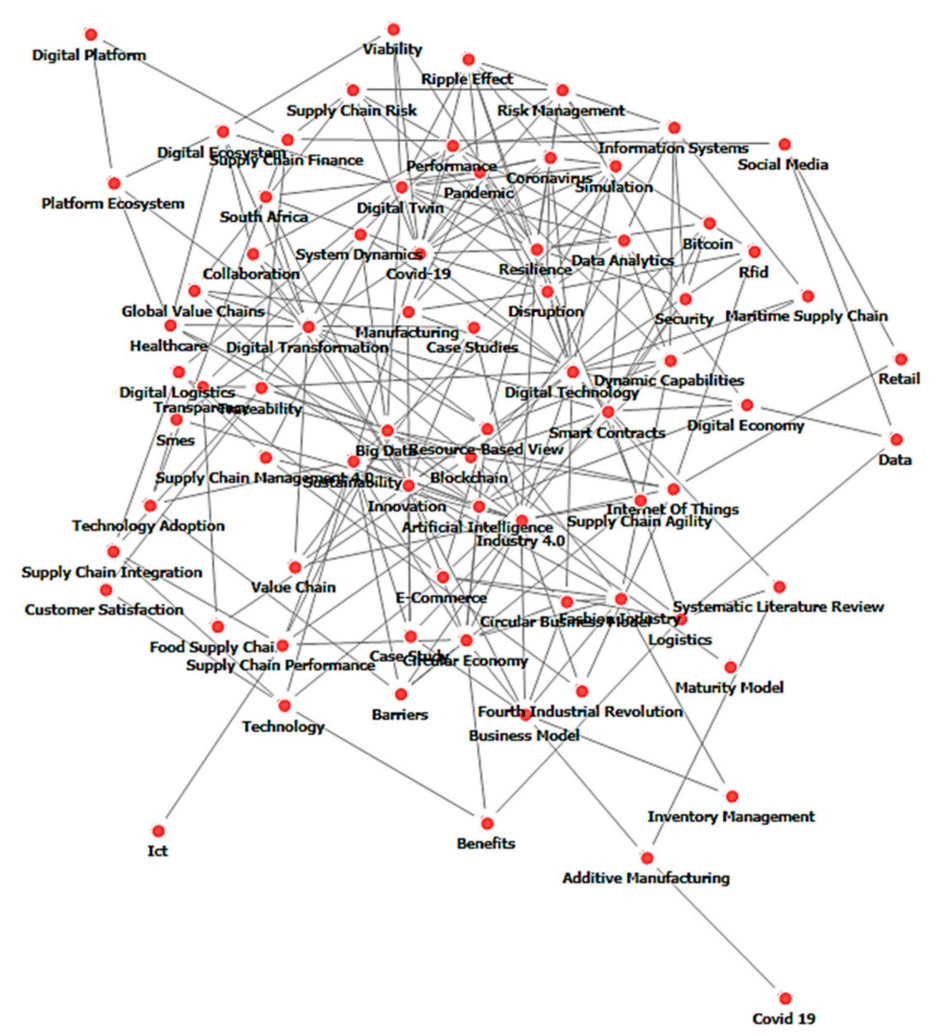

Figure 6. Keyword network (from 2020).

The first cluster includes keywords on supply chain integration and new business models using digital technology. Fatorachian and Kazemi [53] mentioned that digitalization enables process integration in the supply chain, through which flexibility and agility are obtained, thus improving the overall performance of the supply chain. Zeng et al. [54] presented a case study on Italian SMEs to prove that new business models can be created using digital technology such as blockchain in a food supply chain. 
Table 7. Degree centrality analysis (from 2020).

\begin{tabular}{|c|c|}
\hline Keywords & Degree Centrality \\
\hline Digital Technology & 0.256757 \\
\hline Industry 4.0 & 0.243243 \\
\hline Resilience & 0.22973 \\
\hline Innovation & 0.202703 \\
\hline COVID-19 & 0.202703 \\
\hline Digital Transformation & 0.189189 \\
\hline Digital Twin & 0.175676 \\
\hline Sustainability & 0.162162 \\
\hline Blockchain & 0.162162 \\
\hline Disruption & 0.162162 \\
\hline Circular Economy & 0.148649 \\
\hline Coronavirus & 0.135135 \\
\hline Simulation & 0.121622 \\
\hline Artificial Intelligence & 0.121622 \\
\hline Big Data & 0.121622 \\
\hline Risk Management & 0.121622 \\
\hline Data Analytics & 0.121622 \\
\hline Business Model & 0.108108 \\
\hline Pandemic & 0.108108 \\
\hline Resource-Based View & 0.108108 \\
\hline Dynamic Capabilities & 0.108108 \\
\hline Fashion Industry & 0.108108 \\
\hline Smart Contracts & 0.108108 \\
\hline Ripple Effect & 0.108108 \\
\hline Internet of Things & 0.094595 \\
\hline Information Systems & 0.094595 \\
\hline Performance & 0.094595 \\
\hline E-Commerce & 0.081081 \\
\hline
\end{tabular}

The second cluster includes keywords related to COVID-19 and supply chain resilience. Many studies have argued that COVID-19 has increased risk factors such as global supply chain disruptions, which is why global firms must monitor the supply chain in real time by securing end-to-end visibility and making corporate-level efforts to build a digital supply chain to instantly detect and deal with risk-related factors [55-58]. A digital supply chain helps the supply chain gain viability as an ecosystem beyond temporarily improving resilience [57].

The third cluster includes keywords on various digital technologies that are necessary for building a sustainable digital supply chain. Many studies mention blockchain, IoT, artificial intelligence, big data, additive manufacturing, cloud computing, and cyberphysical systems (CPS) as the core digital technologies needed to build a digital supply chain and forecast that more firms will carry out supply chain digitalization once their factors such as security and accessibility are improved [53,59-63]. 
Table 8. Betweenness centrality analysis (from 2020).

\begin{tabular}{|c|c|}
\hline Keywords & Node Betweenness Centrality \\
\hline Digital Technology & 0.157578 \\
\hline Industry 4.0 & 0.145707 \\
\hline Digital Transformation & 0.086762 \\
\hline Blockchain & 0.08134 \\
\hline Innovation & 0.079363 \\
\hline Sustainability & 0.076611 \\
\hline Resilience & 0.070143 \\
\hline COVID-19 & 0.052188 \\
\hline Digital Twin & 0.047308 \\
\hline Business Model & 0.046842 \\
\hline Circular Economy & 0.046083 \\
\hline Internet of Things & 0.038434 \\
\hline Big Data & 0.037876 \\
\hline Traceability & 0.034921 \\
\hline Supply Chain Finance & 0.03312 \\
\hline Supply Chain Performance & 0.032956 \\
\hline Logistics & 0.028666 \\
\hline Additive Manufacturing & 0.027834 \\
\hline Artificial Intelligence & 0.026272 \\
\hline Resource-Based View & 0.025894 \\
\hline Systematic Literature Review & 0.02343 \\
\hline Data Analytics & 0.022839 \\
\hline Supply Chain Risk & 0.022554 \\
\hline Dynamic Capabilities & 0.022045 \\
\hline Fashion Industry & 0.021602 \\
\hline Smart Contracts & 0.020747 \\
\hline Disruption & 0.020117 \\
\hline
\end{tabular}

The fourth cluster is related to building a new ecosystem and value chain through the digital transformation of the supply chain. According to Seyedghorban et al. [64], the emergence of the era of digital transformation has increased the need for a connected ecosystem, forcing many firms to modify their existing supply chain management strategies; thus, digital supply chain management can be an alternative.

The final cluster comprises keywords on collaboration and dynamic capabilities among firms necessary for building and operating a digital supply chain. To successfully build a digital supply chain, firms need dynamic capabilities to explore new technologies and management techniques and implement them on a timely basis [65]. Moreover, data sharing is essential for the effective operation of digital supply chains, which is why strategic collaboration among firms based on trust is needed, and digital supply chains improve relationship performance among firms functioning collectively as an ecosystem [66]. 


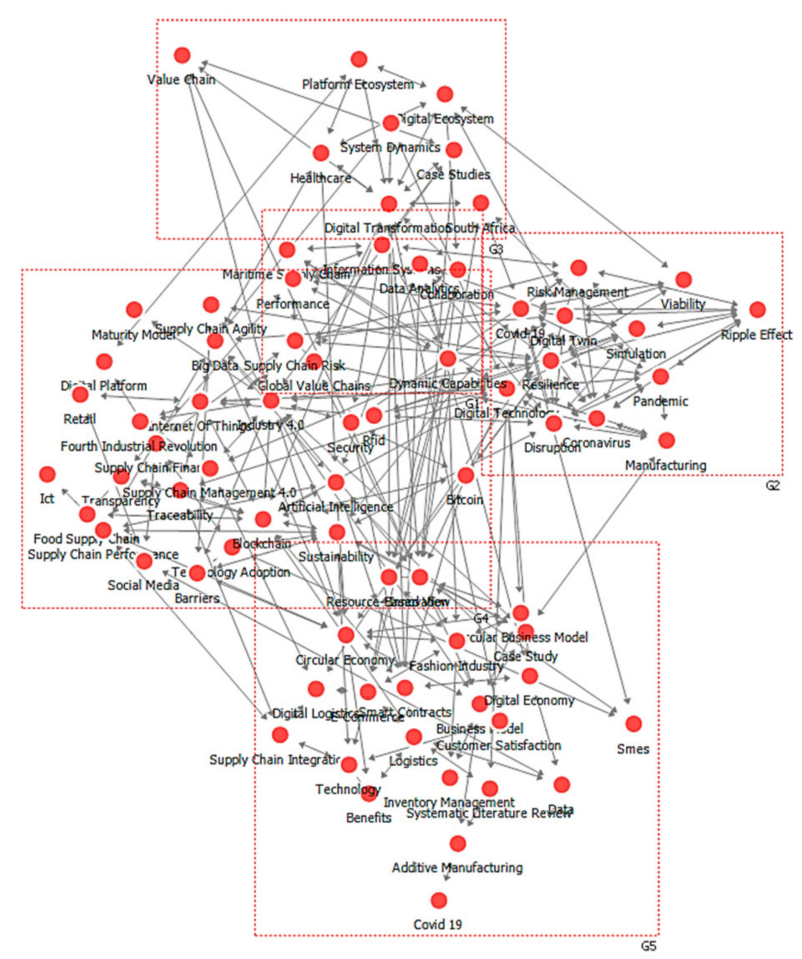

Figure 7. Cluster analysis (from 2020).

Table 9. Main keywords by cluster (from 2020).

\begin{tabular}{|c|c|c|}
\hline Cluster & Main Keywords & Related Topics \\
\hline 1 & $\begin{array}{l}\text { Business Model, Supply Chain } \\
\text { Integration, Digital Economy }\end{array}$ & $\begin{array}{l}\text { Studies on supply chain integration and new } \\
\text { business models using digital technology with } \\
\text { the emergence of the era of digital economy }\end{array}$ \\
\hline 2 & $\begin{array}{l}\text { COVID-19, Disruption, Risk } \\
\text { Management, Resilience, Viability }\end{array}$ & $\begin{array}{c}\text { Studies on digital supply chain as a strategy to } \\
\text { promote supply chain resilience as COVID-19 } \\
\text { has increased the supply chain risks }\end{array}$ \\
\hline 3 & $\begin{array}{l}\text { Sustainability, Blockchain, } \\
\text { Internet of Things, Artificial } \\
\text { intelligence, Big Data }\end{array}$ & $\begin{array}{l}\text { Studies on various digital technologies necessary } \\
\text { for building a sustainable digital supply chain }\end{array}$ \\
\hline 4 & $\begin{array}{l}\text { Digital Transformation, Digital } \\
\text { Ecosystem, Value Chain }\end{array}$ & $\begin{array}{c}\text { Studies on building a new ecosystem and value } \\
\text { change due to digital transformation of supply } \\
\text { chains }\end{array}$ \\
\hline 5 & $\begin{array}{l}\text { Collaboration, Dynamic } \\
\text { Capability, Performance }\end{array}$ & $\begin{array}{l}\text { Studies on collaboration and dynamic } \\
\text { capabilities among firms, which are necessary } \\
\text { for building and operating a digital supply chain }\end{array}$ \\
\hline
\end{tabular}

\section{Conclusions}

This study conducted a network text analysis by combing 815 articles on digital supply chains on Scopus to identify research trends. The results of the analysis are summarized as follows. First, many studies have examined the digital supply chain in terms of sustainable management. "Sustainability" was the most influential word in the keyword network, and the digital transformation of supply chains is essential for the sustainable viability of firms in the era of Industry 4.0 and digital transformation. Accordingly, supply chain strategies, value chains, business models, and business ecosystems ought to be reshaped [67]. Second, the use of digital technologies is crucial for implementing digital supply chains, and technologies such as blockchain, digital twin, additive manufacturing, cloud computing, big data, artificial intelligence, digital manufacturing, and IoT have been presented in many studies. These digital technologies not only connect the supply chains in firms but also 
enable stakeholders in the overall supply chain to have end-to-end visibility on a real-time basis for ensuring its operation as a single organic system. Many studies have mentioned that the performance of supply chains can be improved by conducting various analyses based on the data collected from supply chains. Third, researchers have shown significantly more interest in digital supply chain management during the COVID-19 pandemic. Factories have been shut down all over the world because of COVID-19. Supply chain disruptions worsened without a smooth supply of materials, parts, and equipment. Thus, firms have been actively pursuing supply chain digitalization to improve their resilience during COVID-19. Studies have shown that supply chains evolve into a single ecosystem through integration. Fourth, major groups of research topics can be found through cluster analysis of the keyword network. This study analyzed the articles by dividing them into two groups dating to the times before and after the outbreak of COVID-19, and the results showed that the common groups of keywords were related to "supply chain integration", "resilience", "digital technologies", and "digital transformation". This is summarized in Table 10.

Table 10. Keyword clusters.

\begin{tabular}{|c|c|}
\hline Main Clusters of Keywords & Related Studies \\
\hline $\begin{array}{l}\text { Industry 4.0, Digital } \\
\text { Transformation }\end{array}$ & $\begin{array}{l}\text { The mega trends such as that of Industry } 4.0 \text { and digital } \\
\text { transformation demand digital transformation of supply chains. } \\
\text { It is necessary to establish general business strategies for the } \\
\text { digital transformation of supply chains and reconsider existing } \\
\text { business models and value chains. }\end{array}$ \\
\hline Supply Chain Integration & $\begin{array}{l}\text { Digital supply chains reinforce supply chain integration into a } \\
\text { complicated global network beyond simple and linear supply } \\
\text { chains. }\end{array}$ \\
\hline Resilience & $\begin{array}{l}\text { A digital supply chain ultimately enables real-time end-to-end } \\
\text { visibility and improves resilience. } \\
\text { Supply chain risk management must be done with a focus on } \\
\text { digitalization, especially in view of COVID-19. }\end{array}$ \\
\hline Digital Technologies & $\begin{array}{l}\text { A digital supply chain is not built at once in a short time but } \\
\text { must be built by applying, step by step, various digital } \\
\text { technologies. } \\
\text { Due to the nature of supply chains, performance cannot be } \\
\text { easily improved when only focal firms are digitalized. The } \\
\text { supply chain must be digitalized overall by digitalizing small } \\
\text { and medium-sized firms in the supply chain as well. }\end{array}$ \\
\hline
\end{tabular}

This study has several implications. First, it quantified and systematically identified research trends in the digital supply chain through network analysis. Keyword data were used in blocks of unstructured text data to build matrices and keyword networks and conduct degree centrality, betweenness centrality, and cluster analyses. Thus, research trends could be identified objectively through quantified data.

Second, the research trends were analyzed by dividing the time period between the era before and after the outbreak of the COVID-19 pandemic, thereby analyzing the most recent trends in research on digital supply chain management. As uncertainties have been increasing and stability has been decreasing in global supply chains since the pandemic, studies on digital supply chains have increased not only in terms of the number of published papers from a quantitative perspective, but also in terms of the range and scope of topics from a qualitative perspective. Due to the fact that there usually exists a gap in time falling between the point when research articles are studied and written and the point when they are published, the number of research articles on topics combining COVID-19 and digital supply chains will rapidly increase in the future. In particular, 
as uncertainties in supply chain operations increase with the collapse and disruption of supply chains, the importance of predictive analytics based on the results obtained from simulations such as CPS and digital twin technology has increased. This gives rise to the need for research on big data analysis and the utilization of intelligent decision-making systems applying AI based on deep learning (DL) and ML. Furthermore, it will also be meaningful to prove that the results of simulation-based prescriptive analytics using CPS or digital twins are effective in handling and coping with complicated problems in practice.

\section{Future Research and Limitations}

The topics that require further research can be identified through research trend analysis. Based on literature review and analysis, the most important feature for innovation in the digital supply chain can be summarized as COVID-R (COnnectivity, Visibility, Intelligent Decision making, and Resilience). In other words, the key function of the digital supply chain is to secure supply chain visibility by connecting the current status of operations performed by the entities in a supply chain and real-time monitoring of incidents using state-of-the-art digital technologies, and to quickly recover their correlated functions by making immediate decisions in accordance with the response scenarios that were prepared for in advance.

This method of operations requires studies that consider a decentralized operating system instead of those focused on the focal firm's centralized operating system, which has been emphasized in extant studies on supply chains and related fields. More specifically, supply chains concentrating on focal firms focus on "centralized functionalities" by perceiving a series of activities such as the procurement of materials and components, product manufacturing, distribution and storage, and sales in a linear pattern implemented consecutively. On the other hand, digital supply chains emphasize "centralized informativeness" using platforms, and each function can be performed through decentralization. For example, in a conventional supply chain, products are manufactured by a manufacturing company that is mostly perceived as a focal firm; however, in a digital supply chain that uses 3D-printing technology, the manufacturing function can be performed in places other than the focal firm. Therefore, research must also be conducted on new and diverse business models that consider digital supply chains. In this context of decentralization, changes in organizational operations as well as governance among organizations are expected [68]. Thus, it is necessary to study new topics that consider governance issues among organizations from the perspective of extended enterprises.

In addition, in summary of articles already published, studies have been actively but independently conducted on supply chain integration, resilience, and digital technology, but not enough studies have combined these concepts. There are also few studies on management issues among firms that may arise when building a digital supply chain. For example, whereas subordinate business relations focused on focal firms are generally a feature of conventional supply chain operations, if digitalization is implemented by force, without proper understanding of supply chain digitalization among entities, some suppliers may refuse to share information they are privy to or have concerns about unfair trade, thereby negatively impacting the digital supply chain and betraying opportunistic behavior [69]. This may also have a negative impact on long-term business relations between buyers and suppliers [66] and even cause firms to incur transaction costs [70]. These drawbacks can be alleviated by the exchange of information, requests of or recommendations for partners, and adequate emphasis on building social capital [71,72]. Therefore, it is necessary to support the understanding and sharing of information about supply chain digitalization among firms that share business relations within the supply chain, which plays a critical role in reducing information asymmetry in the supply chain [73]. Offering a higher level of information is beneficial for reducing suppliers' opportunistic attitudes [74]. As mentioned earlier, supply chain digitalization requires a concentration of information in operations, which may violate the autonomy of trade partners [75], thereby possibly causing side effects such as authority costs [76]. Therefore, it is necessary to conduct stud- 
ies on firms that collaborate and share information on performance by building a digital supply chain in terms of business ecosystems [77] based on mutual trust and analyze how this improves firms' performance indicators, including both financial and non-financial indexes. The cyber-physical connectivity creates problems regarding the technological differences between developed and developing countries when considering the successful implementation of various supply chain functions including procurement, manufacturing, logistics, data securities, etc. Therefore, this is also another important topic of future study.

This study has several limitations. First, since the articles are searched only on Scopus, some studies with a large number of citations may have been omitted from the subjects of analysis. Further research must use various academic databases, such as Google Scholar and Web of Science. Second, this study conducted an inadequate analysis of highly influential articles or authors since it was focused on the keyword network. Even though we provide tables showing major journals and authors publishing digital supply chain articles, we did not analyze the co-authorship network, co-citation network, and clusters of researchers and articles on digital supply chain management. Future analysis of research trends must identify influential articles and authors by building citation networks, co-citation networks, and author networks.

Author Contributions: Conceptualization, J.P. and J.S.R.; methodology, J.P. and J.S.R.; software, J.S.R.; validation, J.P. and J.S.R.; formal analysis, J.P. and J.S.R. All authors have read and agreed to the published version of the manuscript.

Funding: The present research was supported by the research fund of Dankook University in 2021.

Acknowledgments: Thank you to the anonymous peer reviewers and the editors for their critical comments, which helped to improve significantly the quality of this paper.

Conflicts of Interest: The authors declare no conflict of interest.

\section{References}

1. Garay-Rondero, C.L.; Martinez-Flores, J.L.; Smith, N.R.; Morales, S.O.C.; Aldrette-Malacara, A.J. Digital supply chain model in Industry 4.0. Manuf. Technol. Manag. 2020, 31, 887-933. [CrossRef]

2. Daniel, D. Digital Supply Chain. SearchERP.com. Available online: https://searcherp.techtarget.com/definition/digital-supplychain?vgnextfmt=print (accessed on 22 March 2021).

3. Kinnet, J. Creating a Digital Supply Chain: Monsanto's Journey, SlideShare, 1-16. Volume 21. Available online: https://www. slideshare.net/BCTIM/creating-a-digital-supply-chain-monsantos-journey (accessed on 21 June 2015).

4. Wu, L.; Yue, X.; Jin, A.; Yen, D.C. Smart supply chain management: A review and implications for future research. Int. J. Logist. Manag. 2016, 27, 395-417. [CrossRef]

5. PwC. Industry 4.0 \& How Digitization Makes the Supply Chain More Efficient, Agile, and Customer-Focused. 2016. Available online: https:/ / www.strategyand.pwc.com/gx/en/insights/2016/digitization-more-efficient.html (accessed on 22 March 2021).

6. Agile Elephant. What Is Digital Transformation. Available online: www.theagileelephant.com/what-is-digital-transformation (accessed on 22 March 2021).

7. Büyüközkan, G.; Göçer, F. Digital Supply Chain: Literature review and a proposed framework for future research. Comput. Ind. 2018, 97, 157-177. [CrossRef]

8. Bhargava, B.; Ranchal, R.; Ben Othmane, L. Secure information sharing in digital supply chains. In Proceedings of the 20133 rd IEEE International Advance Computing Conference (IACC), Ghaziabad, India, 22-23 February 2013; pp. $1636-1640$.

9. Raab, M.; Griffin-Cryan, B. Digital Transformation of Supply Chains: Creating Value-When Digital Meets Physical. 2011. Available online: https://www.capgemini.com/wpcontent/uploads/2017/07/Digital_Transformation_of_Supply_Chains.pdf (accessed on 22 March 2021).

10. The Centre for Global Enterprise. Digital Supply Chains: A Frontside Flip. 2016. Available online: https://www.dscinstitute.org/ assets/documents/a-frontside-flip_white-paper_english-version.pdf (accessed on 28 April 2021).

11. Wijoyo, S.; Abrianto, B.O.; Aris, M.S.; Nugraha, X.; Frisa, K.A.M. Digital Supply Chain Mechanism in Indonesian Society and Industrialization. Int. J. Supply Chain Manag. 2020, 9, 509-518.

12. Digital Supply Chain Institute. Digital Supply Chain Transformation Guide: Essential Metrics; The Centre for Global Enterprise: New York, NY, USA, 2017.

13. Kodolova, I.A.; MirgaziyanovnaYusupova, L.; Viktorovna Nikonova, T.; Kalimullina, R.R. Development of Innovative Activity and Supply Chain Strategy of Enterprises in the Age of Digital Economy. Int. J. Supply Chain Manag. 2019, 8, 525-531.

14. Accenture. Supply Chain Transformation on the Cloud. Available online: https://www.accenture.com/us-en/insights/supplychain-operations / supply-chain-transformation-cloud (accessed on 13 July 2021). 
15. Klötzer, C.; Pflaum, A. Toward the Development of a Maturity Model for Digitalization within the Manufacturing Industrys Supply Chain. In Proceedings of the 50th Hawaii International Conference on System Sciences, Waikoloa Village, HI, USA, 4-7 January 2017; pp. 4210-4219.

16. Kartskhiya, A.A.; Tyrtychnyy, S.A.; Smirnov, M.G.; Dolgikh, M.G.; Khmelnitskiy, L.A. Digital Technologies in Supply Chain Management for Production and Digital Economy Development. Int. J. Supply Chain Manag. 2020, 9, 912-918.

17. Simchenko, N.A.; Tsohla, S.Y.; Chyvatkin, P.P. IoT \& Digital Twins Concept Integration Effects on Supply Chain Strategy: Challenges and Effect. Int. J. Supply Chain Manag. 2019, 8, 803-808.

18. Cecere, L. Embracing the Digital Supply Chain. 2016. Available online: https://www.supplychainshaman.com/demand/ demanddriven/embracing-the-digital-supply-chain (accessed on 22 March 2021).

19. Di Nardo, M. Developing a Conceptual Framework Model of Industry 4.0 for Industrial Management. Ind. Eng. Manag. Syst. 2020, 19, 551-560. [CrossRef]

20. Ivanov, D.; Dolgui, A.; Sokolov, B. The impact of digital technology and Industry 4.0 on the ripple effect and supply chain risk analytics. Int. J. Prod. Res. 2019, 57, 829-846. [CrossRef]

21. Calatayud, A.; Mangan, J.; Christopher, M. The self-thinking supply chain. Supply Chain Manag. Int. J. 2019, 24, 22-38. [CrossRef]

22. Kearney, A.T. Digital Supply Chains: Increasingly Critical for Competitive Edge; The Centre for Global Enterprise: New York, NY, USA, 2015.

23. OECD. Available online: https:/ / www.oecd.org/economic-outlook/june-2020 (accessed on 13 July 2021).

24. Simchi-Levi, D.; Simchi-Levi, E. We Need a Stress Test for Critical Supply Chains. Harv. Bus. Rev. 2020. Available online: https:/ / hbr-org.cdn.ampproject.org/c/s/hbr.org/amp/2020/04/we-need-a-stress-testfor-critical-supply-chains (accessed on 22 July 2020).

25. Digital Supply Chain Institute. Bamboo Supply Chain: Resiliency in the Time of COVID-19; The Centre for Global Enterprise: New York, NY, USA, 2020.

26. Iddris, F. Digital Supply Chain: Survey of the Literature. Int. J. Bus. Res. Manag. 2018, 9, 47-61.

27. Robotics \& Automation News. 2020. Available online: https:// roboticsandautomationnews.com (accessed on 21 January 2021).

28. USA Today. Available online: https:/ / www.usatoday.com/story/tech/2020/07/22/amazon-taking-its-scout-delivery-robotssouth/5485106002 (accessed on 22 July 2020).

29. Amazon. Now-Has-200,000-Robots-Working-in-Its-Warehouses. Available online: https:/ / roboticsandautomationnews.com/ 2020/01/21/amazon-now-has-200000-robots-working-in-its-warehouses (accessed on 22 March 2021).

30. LCLO. Available online: https:/ / clomag.co.kr/article/3393 (accessed on 13 July 2021).

31. Samsung SDS. Available online: https://www.samsungsds.com/kr/scm/scm.html (accessed on 13 July 2021).

32. Alonso-Muñoz, S.; González-Sánchez, R.; Siligardi, C.; García-Muiña, F. New Circular Networks in Resilient Supply Chains: An External Capital Perspective. Sustainability 2021, 13, 6130. [CrossRef]

33. UKRI. Available online: https://www.ukri.org/opportunity/manufacturing-made-smarter-innovation-hub-digital-supplychain (accessed on 13 July 2021).

34. Cabinet Office, Government of Japan. Available online: https://www8.cao.go.jp/cstp/english/society5_0/manufacturing_e. html (accessed on 13 July 2021).

35. White House. Available online: https://www.whitehouse.gov/briefing-room/presidential-actions/2021/02/24/executiveorder-on-americas-supply-chains (accessed on 13 July 2021).

36. Fahimnia, B.; Sarkis, J.; Davarzani, H. Green supply chain management: A review and bibliometric analysis. Int. J. Prod. Econ. 2015, 162, 101-114. [CrossRef]

37. Fahimnia, B.; Tang, C.S.; Davarzani, H.; Sarkis, J. Quantitative models for managing supply chain risks: A review. Eur. J. Oper. Res. 2015, 247, 1-15. [CrossRef]

38. Feng, Y.; Zhu, Q.; Lai, K.-H. Corporate social responsibility for supply chain management: A literature review and bibliometric analysis. J. Clean. Prod. 2017, 158, 296-307. [CrossRef]

39. Rha, J.S. Trends of Research on Supply Chain Resilience: A Systematic Review Using Network Analysis. Sustainability 2020, 12, 4343. [CrossRef]

40. Blondel, V.D.; Guillaume, J.L.; Lambiotte, R.; Lefebvre, E. Fast Unfolding of Communities in Large Networks. J. Stat. Mech. Theor. Exp. 2008, 10, 10008. [CrossRef]

41. Hosseini, S.; Ivanov, D.; Dolgui, A. Review of quantitative methods for supply chain resilience analysis. Transp. Res. Part E Logist. Transp. Rev. 2019, 125, 285-307. [CrossRef]

42. Saberi, S.; Kouhizadeh, M.; Sarkis, J.; Shen, L. Blockchain technology and its relationships to sustainable supply chain management. Int. J. Prod. Res. 2019, 57, 2117-2135. [CrossRef]

43. Ranganathan, C.; Teo, T.S.; Dhaliwal, J. Web-enabled supply chain management: Key antecedents and performance impacts. Int. J. Inf. Manag. 2011, 31, 533-545. [CrossRef]

44. Bienhaus, F.; Haddud, A. Procurement 4.0: Factors influencing the digitisation of procurement and supply chains. Bus. Process. Manag. J. 2018, 24, 965-984. [CrossRef]

45. Foster, C.; Graham, M.; Mann, L.; Waema, T.; Friederici, N. Digital Control in Value Chains: Challenges of Connectivity for East African Firms. Econ. Geogr. 2018, 94, 68-86. [CrossRef] 
46. Rai, A.; Patnayakuni, R.; Seth, N. Seth Firm Performance Impacts of Digitally Enabled Supply Chain Integration Capabilities. MIS Q. 2006, 30, 225. [CrossRef]

47. Hsu, C.; Wallace, W.A. An industrial network flow information integration model for supply chain management and intelligent transportation. Enterp. Inf. Syst. 2007, 1, 327-351. [CrossRef]

48. Bharadwaj, S.; Bharadwaj, A.; Bendoly, E. The Performance Effects of Complementarities between Information Systems, Marketing, Manufacturing, and Supply Chain Processes. Inf. Syst. Res. 2007, 18, 437-453. [CrossRef]

49. Rajesh, R. Forecasting supply chain resilience performance using grey prediction. Electron. Commer. Res. Appl. 2016, 20, 42-58. [CrossRef]

50. Graça, P.; Camarinha-Matos, L. Performance indicators for collaborative business ecosystems-Literature review and trends. Technol. Forecast. Soc. Chang. 2017, 116, 237-255. [CrossRef]

51. Bogers, M.; Hadar, R.; Bilberg, A. Additive manufacturing for consumer-centric business models: Implications for supply chains in consumer goods manufacturing. Technol. Forecast. Soc. Chang. 2016, 102, 225-239. [CrossRef]

52. Holmström, J.; Holweg, M.; Khajavi, S.H.; Partanen, J. The direct digital manufacturing (r)evolution: Definition of a research agenda. Oper. Manag. Res. 2016, 9, 1-10. [CrossRef]

53. Fatorachian, H.; Kazemi, H. Impact of Industry 4.0 on supply chain performance. Prod. Plan. Control. 2021, 32, 63-81. [CrossRef]

54. Zeng, F.; Chan, H.K.; Pawar, K. The effects of inter- and intraorganizational factors on the adoption of electronic booking systems in the maritime supply chain. Int. J. Prod. Econ. 2021, 236, 108119. [CrossRef]

55. Ivanov, D.; Dolgui, A. Viability of intertwined supply networks: Extending the supply chain resilience angles towards survivability. A position paper motivated by COVID-19 outbreak. Int. J. Prod. Res. 2020, 58, 2904-2915. [CrossRef]

56. Belhadi, A.; Kamble, S.; Jabbour, C.J.C.; Gunasekaran, A.; Ndubisi, N.O.; Venkatesh, M. Manufacturing and service supply chain resilience to the COVID-19 outbreak: Lessons learned from the automobile and airline industries. Technol. Forecast. Soc. Chang. 2021, 163, 120447. [CrossRef]

57. Ivanov, D. Lean resilience: AURA (Active Usage of Resilience Assets) framework for post-COVID-19 supply chain management. Int. J. Logist. Manag. 2021. [CrossRef]

58. Zouari, D.; Ruel, S.; Viale, L. Does digitalising the supply chain contribute to its resilience? Int. J. Phys. Distrib. Logist. Manag. 2021, 51, 149-180. [CrossRef]

59. Nandi, S.; Sarkis, J.; Hervani, A.A.; Helms, M.M. Redesigning Supply Chains using Blockchain-Enabled Circular Economy and COVID-19 Experiences. Sustain. Prod. Consum. 2021, 27, 10-22. [CrossRef]

60. Qian, X.A.; Papadonikolaki, E. Shifting trust in construction supply chains through blockchain technology. Eng. Constr. Arch. Manag. 2020, 28, 584-602. [CrossRef]

61. Liu, Z.; Li, Z. A blockchain-based framework of cross-border e-commerce supply chain. Int. J. Inf. Manag. 2020, 52, 102059. [CrossRef]

62. D'Adamo, I.; González-Sánchez, R.; Medina-Salgado, M.; Settembre-Blundo, D. E-Commerce Calls for Cyber-Security and Sustainability: How European Citizens Look for a Trusted Online Environment. Sustainability 2021, 13, 6752. [CrossRef]

63. Arora, A.; Arora, A.S.; Sivakumar, K.; Burke, G. Strategic sustainable purchasing, environmental collaboration, and organizational sustainability performance: The moderating role of supply base size. Supply Chain Manag. Int. J. 2020, 25, 709-728. [CrossRef]

64. Seyedghorban, Z.; Tahernejad, H.; Meriton, R.; Graham, G. Supply chain digitalization: Past, present and future. Prod. Plan. Control 2020, 31, 96-114. [CrossRef]

65. Gupta, S.; Modgil, S.; Gunasekaran, A.; Bag, S. Dynamic capabilities and institutional theories for Industry 4.0 and digital supply chain. Supply Chain Forum Int. J. 2020, 21, 139-157. [CrossRef]

66. Ganesan, S. Determinants of Long-Term Orientation in Buyer-Seller Relationships. J. Mark. 1994, 58, 1-19. [CrossRef]

67. Di Nardo, M.; Clericuzio, M.; Murino, T.; Sepe, C. An Economic Order Quantity Stochastic Dynamic Optimization Model in a Logistic 4.0 Environment. Sustainability 2020, 12, 4075. [CrossRef]

68. Di Nardo, M.; Yu, H. Special Issue “Industry 5.0: The Prelude to the Sixth Industrial Revolution”. Appl. Syst. Innov. 2021, 4, 45. [CrossRef]

69. Nasiri, M.; Ukko, J.; Saunila, M.; Rantala, T. Managing the digital supply chain: The role of smart technologies. Technovation 2020, 96, 102121. [CrossRef]

70. Williamson, O.E. Markets and Hierarchies: Analysis and Antitrust Implications; The Free Press: New York, NY, USA, 1975.

71. Wathne, K.H.; Heide, J.B. Opportunism in Interfirm Relationships: Forms, Outcomes, and Solutions. J. Mark. 2000, 64, 36-51. [CrossRef]

72. Villena, V.H.; Revilla, E.; Choi, T.Y. The dark side of buyer-supplier relationships: A social capital perspective. J. Oper. Manag. 2010, 29, 561-576. [CrossRef]

73. Dyer, J.H. Effective Interfirm Collaboration: How Firms Minimize Transaction Costs and Maximize Transaction Value. Strateg. Manag. J. 1997, 18, 535-556. [CrossRef]

74. Wang, Z.; Ye, F.; Tan, K.H. Effects of managerial ties and trust on supply chain information sharing and supplier opportunism. Int. J. Prod. Res. 2014, 52, 7046-7061. [CrossRef]

75. Heide, J.B.; Wathne, K.H.; Rokkan, A.I. Interfirm Monitoring, Social Contracts, and Relationship Outcomes. J. Mark. Res. 2007, 44, 425-433. [CrossRef] 
76. Halaby, C.N. Worker Attachment and Workplace Authority. Am. Sociol. Rev. 1986, 51, 634. [CrossRef]

77. Iansiti, M.; Levien, R. Strategy as Ecology. Harv. Bus. Rev. 2004, 82, 68-78. [PubMed] 